\title{
A GEOGRAFIA NA BASE NACIONAL COMUM CURRICULAR (BNCC): PERCURSOS E PERSPECTIVAS
}

\author{
GEOGRAPHY AT THE NATIONAL CURRICULAR COMMON BASE (BNCC): PATHS AND PERSPECTIVES
}

\author{
GEOGRAFÍA EN LA BASE NACIONAL COMÚN CURRICULAR (BNCC): CAMINOS Y PERSPECTIVAS
}

\section{RESUMO}

Introdução: A Base Nacional Comum Curricular (BNCC) é um documento de caráter normativo, produzido pelo Ministério da Educação (MEC), que define o conjunto orgânico e progressivo de aprendizagens essenciais que todos os alunos devem desenvolver ao longo das diversas etapas e modalidades da Educação Básica. Ao ser promulgada, a BNCC da Educação Infantil e Ensino Fundamental (EI/EF) se tornou a referência nacional para a constituição dos currículos do país. Objetivo: Considerando a importância deste documento para a educação brasileira e para a Geografia, a presente pesquisa buscou discutir a entrada da Geografia escolar no Brasil, a importância do componente curricular nos currículos escolares e, principalmente, sua presença na BNCC. Dessa forma, buscou-se compreender os possíveis impactos no processo de ensino-aprendizagem da Geografia e as implicações para a formação do professor dessa área do currículo escolar. Métodos: 0 estudo seguiu os métodos da pesquisa qualitativa, com especial utilização da análise de conteúdo, elegendo como fonte fundamental de pesquisa a análise de leis e documentos - especialmente o texto da BNCC EI/EF. Resultados: A partir da análise do documento, verificou-se que ele trará uma unificação dos conteúdos a nível nacional, entretanto, foram encontrados diversos retrocessos que incluem desde a explicação incompleta dos conceitos geográficos até uma escassa referência ao trabalho de campo da Geografia. Conclusão: Considerando tais elementos, este artigo almeja contribuir para a melhoria do processo formativo e da prática pedagógica dos professores de Geografia, apontando as mudanças e/ou desafios que enfrentarão na promoção da educação geográfica a partir da implantação da BNCC EI/EF.

Palavras-chave: Base Nacional Comum Curricular. Currículo. Ensino Fundamental. Ensino de Geografia. Brasil.

\section{ABSTRACT}

Introduction: The National Curricular Common Base (BNCC) is a normative document, produced by the Ministry of Education (MEC) which defines the organic and progressive set of essential learning that all students must develop throughout the various stages and modalities of Basic Education. When it was promulgated, the BNCC in Early Childhood Education and Elementary Education (EI/EF) became the national reference for the constitution of curricula from school institutions. Objectives: Considering the importance of this document for Brazilian education and Geography, the present study aimed to discuss the entry of school geography in Brazil, the importance of the curriculum component in school curricula and, especially, its presence in the BNCC. In this way, we sought to understand the possible impacts on the teaching-learning process of geography and the implications for teacher training in this area of the school curriculum. Methods: The study followed the methods of qualitative research, with special use of content analysis, choosing as a fundamental source of research the analysis of laws and documents - especially the BNCC EI / EF text. Results: From the analysis of the document, it was verified that the BNCC EI / EF will bring the unification of contents at national level, however, several setbacks have been found that range from the incomplete explanation of the geographic concepts to a scarce reference to field work of pedagogical work of geography. Conclusion: Considering these elements, this dissertation aims to contribute to the improvement of the formative process and pedagogical practice of Geography teachers, pointing out the changes and/or challenges they will face in the promotion of geographic education from the implementation of BNCC EI/EF.

Keywords: National Curricular Common Base. Curriculum. Elementary School. Geography Teaching. Brazil.
Isadora Pinheiro ${ }^{\text {a }}$

D Claudivan Sanches Lopes ${ }^{a}$

a Universidade Estadual de Maringá (UEM), Maringá, PR, Brasil

DOI: $10.12957 /$ geouerj.2021.45521

Correpondência: claudivanlopes@gmail.com

Recebido em: 24 set. 2019 Aceito em: 14 mar.2021 


\section{RESUMEN}

Introducción: La Base Nacional Común Curricular (BNCC) es un documento de carácter normativo, elaborado por el Ministerio de Educación (MEC) que define el conjunto orgánico y progresivo de aprendizajes esenciales que todo alumno debe desarrollar a lo largo de las distintas etapas y modalidades de la Educación Básica. Cuando se promulgó, la BNCC de Educación Infantil y Educación Fundamental (EI/EF) se convirtió en la referencia nacional para la constitución de los planes de estudio del país. Objetivos: Considerando la importancia de este documento para la educación brasileña y para la Geografía, esta investigación buscó discutir el ingreso de la Geografía escolar en Brasil, la importancia del componente curricular en los currículos escolares y, principalmente, su presencia en la BNCC. Así, se buscó comprender los posibles impactos en el proceso de enseñanza-aprendizaje de la Geografía y las implicaciones para la formación de los docentes en esta área del currículo escolar. Métodos: El estudio siguió los métodos de investigación cualitativa, con especial uso del análisis de contenido, eligiendo como fuente fundamental de investigación el análisis de leyes y documentos, especialmente el texto de la BNCC EI/EF. Resultados: Desde el análisis del documento se verificó que traerá una unificación de los contenidos a nivel nacional, sin embargo, fueron encontrados varios retrocesos que incluyen desde la explicación incompleta de los conceptos geográficos hasta una escasa referencia al trabajo de campo de Geografía. Conclusión: Considerando estos elementos, este artículo tiene como objetivo contribuir al mejoramiento del proceso formativo y la práctica pedagógica de los docentes de Geografía, señalando los cambios y/o desafíos que enfrentarán en la promoción de la educación geográfica a partir de la implementación de la BNCC EI/EF.

Palabras-clave: Base Nacional Común Curricular. Currículo. Enseñanza fundamental. Enseñanza de la Geografía. Brasil. 


\section{INTRODUÇÃO}

A Base Nacional Comum Curricular (BNCC) é o novo parâmetro que vai orientar a organização dos currículos de todas as etapas da Educação Básica: Educação Infantil, Ensino Fundamental e Ensino Médio. Proposta pelo Ministério da Educação (MEC) e aprovada/promulgada em 20 de dezembro de 2017, possui caráter normativo e define o conjunto orgânico e progressivo de aprendizagens consideradas essenciais que todos os alunos devem desenvolver ao longo das diversas etapas e modalidades da Educação Básica. Entendese, desse modo, que a BNCC é um documento muito significativo para a educação brasileira e que, à margem das críticas que a ela podem e, efetivamente, devem ser feitas, pretende guiar os sistemas educacionais na construção de suas propostas curriculares, assim como, em consequência, influenciará a construção dos currículos de formação de professores.

A BNCC não é propriamente um currículo. Entretanto, como mencionado, ao se constituir como referência obrigatória que norteará o decurso de construção dos currículos das escolas, redes públicas e privadas de ensino de todo território nacional, impõe-se aos pesquisadores da área um olhar crítico e profundo sobre ela. Destarte, ao selecionar conteúdos e definir os objetivos que se deseja alcançar, este documento adquire posição central no desenvolvimento curricular do país (incluindo a prática docente mais imediata do professor na sala de aula), bem como influenciará o processo de formação dos professores. Ainda que esteja sujeita a adequações e contextualizações em cada rede de ensino e em cada escola - é a esta que, em última instância, cabe encontrar os meios para alcançar os objetivos - é mister analisá-la, contextualizá-la e compreendê-la. Neste contexto, o objetivo desse artigo, que faz parte dos resultados da dissertação da autora, é analisar, considerando seus fundamentos e intenções, o processo histórico de construção da Base Nacional Comum Curricular, particularmente do componente curricular Geografia e seus possíveis impactos no processo ensino-aprendizagem e na formação do professor. E para se chegar aos resultados, foi necessário antes fazer um levantamento sobre como a Geografia escolar entrou no Brasil e foi trabalhada ao longo dos séculos XX e XXI e também qual a importância da mesma para o currículo das escolas.

Ainda falando em relevância, cabe aqui indagar, qual a importância da temática que aqui se apresenta para análise e debate? Vale dizer que, frequentemente, os países do mundo todo passam por processos de reformulação na educação. Essa ação de modificar as políticas educacionais e os currículos geralmente acontece de acordo com as posições ideológicas de quem está no poder naquele momento e, não raramente, principalmente, nas últimas décadas, sobre grande influência das organizações internacionais, como, por exemplo, do Fundo Monetário Internacional - FMI, Banco Mundial e Organização das Nações Unidas para a Educação, Ciência e Cultura - UNESCO.

A junção desses elementos faz com que os rumos da educação de cada país sejam tomados de acordo com as intenções políticas de determinado governo e na interlocução com instituições e organismos 
internacionais, que geralmente seguem a ideologia neoliberal (mais propriamente, na sujeição a esses organismos) que advogam, frequentemente, sobre a redução ou "otimização" dos investimentos na educação, notadamente, aqueles destinados às camadas mais populares da sociedade.

É neste contexto de tensões, questionamentos e incertezas que nasceram as intenções da pesquisa que ora se consubstancia neste artigo. Sua importância, portanto, justifica-se pela relevância do referido documento em tela para a educação brasileira de modo geral e, particularmente, para a educação geográfica que se realiza no Ensino Fundamental. O estudo deriva, complementarmente, de preocupações da pesquisadora, enquanto professora de Geografia atuante na Educação Básica e que participou do processo de debate a respeito da formulação dos objetivos de conhecimento do componente curricular Geografia para a Segunda Versão da BNCC, quanto aos novos rumos que a disciplina poderia tomar se acatada as modificações propostas na época.

Desse modo, o contexto mais amplo de reformas educacionais pelas quais passa a sociedade brasileira (controversas e, portanto, geradora de tensões) e, mais especificamente, os debates vivenciados pela pesquisadora, a levaram a refletir sobre qual será o impacto que a BNCC causará na disciplina de Geografia ante as mudanças que ela propõe. Entende-se ser importante analisar se a BNCC traz a relevância necessária ao trabalho da Geografia nas diversas etapas do ensino, uma vez que esta proporciona aos alunos a compreensão do espaço geográfico de onde vivem, além de ajudá-los no entendimento do mundo globalizado.

A corrente teórico-metodológica escolhida para orientar a produção da presente dissertação insere-se no bojo das pesquisas intituladas crítico-dialéticas. Esse tipo ou modo de compreensão da investigação científica é dotado de algumas características específicas entre as quais se destacam, segundo Gamboa (1989), a incorporação de dados contraditórios; postura fortemente crítica; fundamentação teórica a partir das categorias de análise e o resgate da dimensão histórica dos fatos trazidos para análise.

Seguindo, portanto, a lógica da concepção crítica-dialética, a investigação que aqui se apresenta está situada, paradigmaticamente, no campo das pesquisas qualitativas, tendo, como fontes principais de coleta de dados a análise bibliográfica e a análise de conteúdos, destacadamente, o texto da BNCC e seu contexto de produção.

Por fim, ao entregar esse artigo ao exame crítico dos leitores, espera-se que ela possa colaborar com os professores da Educação Básica, principalmente os da Geografia, em uma reflexão sobre os novos rumos da Geografia escolar no Brasil. A autora também visa auxiliar com reflexões para a construção dos currículos da Geografia, considerando os avanços e retrocessos que foram destacados na presente pesquisa. 


\section{A PRESENÇA DA GEOGRAFIA NO CURRÍCULO DA EDUCAÇÃO BÁSICA}

A Geografia começa a compor os currículos escolares, no Brasil, no século XIX. Segundo Vlach (2004), a implantação da Geografia nos currículos das escolas brasileiras aconteceu, primeiramente, no Colégio Pedro II, no Rio de Janeiro, então Distrito Federal. Esse colégio foi o primeiro a adotar a disciplina em seu currículo escolar, por meio do Decreto de 2 de dezembro de $1837^{1}$, sendo que, posteriormente, se disseminou pelo resto do país. Seu objetivo, de início, foi tornar os alunos cidadãos, transmitindo conteúdos genéricos sobre o mundo, se embasando na Geografia tradicional, muito difundida na época.

O modelo tradicional da Geografia trabalhava abundantemente com a descrição de lugares, impondo aos alunos o que se convencionou denominar popularmente de "decoreba". Essa forma de ensino era baseada no modelo francês, principalmente nos compêndios de Geografia que eram importados da França.

De modo geral as aulas de Geografia permaneceram nesse formato, ou seja, baseada na descrição e nos exercícios mnemônicos por anos, até que, na década de 1920, se iniciam algumas transformações nessa disciplina escolar. Segundo Rocha (1996), nessa época surgiram oposições em relação ao modelo de Geografia tradicional, culminando em uma nova proposta de ensino, que foi oficializada a partir da implementação do Decreto 16.782a , de 13 de janeiro de 1925, mais conhecida por Lei Rocha Vaz, formulada pelo jurista João Luiz Alves. Com a grande onda de questionamentos a respeito da educação da época, a Geografia conseguiu adentrar nas legislações educacionais (ROCHA, 1996).

De acordo com Rocha (1996), as indagações feitas ao ensino, de modo geral e particularmente ao de Geografia, na época, abarcavam não só a metodologia utilizada, mas também o tratamento didático e os conteúdos trabalhados em sala de aula. Um dos líderes desse movimento foi Carlos Miguel Delgado de Carvalho, professor de Geografia e Sociologia e diretor do Colégio Pedro II, no início do século XX.

As décadas de 1960 e 1970 proporcionaram uma mudança radical não só na Geografia como nas outras disciplinas que tradicionalmente compõe os currículos escolares, decorrentes fundamentalmente do golpe militar que instituiu a partir de março de 1964 (até 1985) o período da Ditadura. Durante esses 21 anos, sob um rígido controle ideológico, a disciplina Geografia (e posteriormente os Estudos Sociais) serviu aos militares como ferramenta ideológica, pois os conhecimentos previstos na organização curricular passaram a ter um caráter de exaltação à Pátria e vazio de conteúdos pedagógico-geográficos significativos.

\footnotetext{
${ }^{1}$ Esse decreto converteu o Seminário de São Joaquim em Colégio Pedro Il e deu outras disposições, dentre elas, a implementação da disciplina de geografia através do artigo 3 que dizia: "Neste colégio serão ensinadas as línguas latina, grega, francesa e inglesa; retórica e os princípios elementares de geografia, história, filosofia, zoologia, mineralogia, botânica, química, física, aritmética, álgebra, geometria e astronomia" (BRASIL, 1837, p. 60).
} 
Desse modo, na esteira das ações promovidas pela Ditadura Militar procedeu-se por meio da aprovação da Lei 5.692/1971, a instituição “[...] dos estudos sociais e se verifica o surgimento de uma Geografia escolar muito conservadora, atrelada a perspectiva pedagógica tecnicista" (ALBUQUERQUE, 2011, p. 24). A nova Lei 5.692/71 substituiu quase integralmente a LDBEN 4.024/61 em vista dos princípios de um novo momento da sociedade brasileira (JACOMELI, 2010).

Portanto, criada no período do Governo Militar, a área² de Estudos Sociais substituiu a Geografia e a História no currículo das escolas brasileiras, resultando em um inequívoco retrocesso nas conquistas que a Geografia, bem como a História, havia conseguido até então. A nova disciplina escolar não se aprofundava nos conteúdos geográficos e nem nos históricos, manifestando seu caráter vazio, superficial e, pretensiosamente, neutro. Segundo Pontuschka (1999), a junção das disciplinas aconteceu de forma autoritária, objetivando transformar a História e a Geografia em matérias inexpressivas dentro do currículo e segmentar ainda mais seu conhecimento.

Neste mesmo período, com a influência principalmente da Geografia Crítica, mas não apenas dela, a Geografia escolar começou a incorporar um discurso politicamente engajado e preocupado com a transformação da realidade social. Questionava a pretensa neutralidade científica que, em certa medida, marcava a chamada Geografia tradicional e que, destacadamente, era o mote fundamental dos conteúdos veiculados pelos Estudos Sociais.

Aos poucos, esse viés crítico foi se expandindo pelo Brasil e adentrando as discussões que transcorriam na escola. A chegada do movimento da Geografia Crítica iniciou-se com um processo que incitou mudanças na forma de se dar aula, no próprio pensamento geográfico, na renovação dos conteúdos e também na valorização de certas atitudes (a ética, o combate aos preconceitos, o respeito as diferenças, etc.) e habilidades (raciocínio, capacidade de observação e crítica, etc.) necessárias aos novos tempos (VESENTINI, 2004).

Avançando alguns anos, mais precisamente em 1996, a LDBEN 9.394 foi promulgada. Segundo Pontuschka, Paganelli e Cacete (2007), essa lei proporcionou mudanças significativas na educação a partir das discussões que ocorreram no universo educacional brasileiro. As propostas curriculares que existiam até então foram novamente

debatidas com o propósito de gerar uma nova proposta que contemplasse todo o país. O resultado desses debates foi a divulgação dos Parâmetros Curriculares Nacionais - PCNs do Ensino Fundamental e Médio.

${ }^{2}$ Importante observar que os Estudos Sociais era uma área que, na prática, transformou-se em uma disciplina. 
De acordo com o Ministério da Educação (BRASIL, 1997), os PCNs buscavam orientar professores e equipe pedagógica na construção de seus currículos, fazendo isso de forma flexível, por ter sua natureza aberta. Na esfera do PCN de Geografia, Sposito (1999) relaciona em seu texto alguns pontos positivos e negativos do documento. De início, a autora salienta que se observa na leitura do documento uma pluralidade teórico-metodológica a qual rompe "[...] tanto com o positivismo como com o marxismo ortodoxo. Buscam-se explicações mais plurais, que promovam a intersecção da Geografia com outros campos do saber como a Antropologia, a Sociologia, a Biologia, as Ciências Políticas, por exemplo" (SPOSITO, 1999, p. 30).

A autora quer dizer que os PCNs vieram com o propósito de valorizar a interdisciplinaridade e favorecer o diálogo entre as disciplinas. Porém, Pizzato $(2001$, p. 79) expõe que esse propósito pode não ser positivo como se imaginava a priori, pois ele representou também a "[...] tendência ao enfraquecimento das disciplinas [...]". Ou seja, a perspectiva de interdisciplinaridade assumida pelo documento acaba não permitindo um aprofundamento dos conhecimentos de cada matéria, pois como o diálogo com as outras disciplinas é fundamental, muitas vezes, o que se é trabalhado em sala acaba sendo uma temática mais geral, superficial, para dar conta de fazer esse diálogo.

Anos após a divulgação dos PCNs no país, no estado do Paraná surgiram as Diretrizes Curriculares Estaduais da Educação Básica do Paraná (DCE-PR), as quais passaram por um processo de elaboração contando com a presença dos professores da Rede Pública Estadual do Paraná (PARANÁ, 2008). Segundo Girotto e Rech (2016), a DCE-PR possui o objetivo de ser um documento mais aberto, que possibilite aos vários sujeitos da educação a produção de propostas de ensino de Geografia “[...] sem que haja a obrigatoriedade de um currículo unificado. $\mathrm{O}$ documento está organizado em conteúdos estruturantes (as dimensões do espaçogeográfico) e aponta alguns objetivos para o Ensino de Geografia" (GIROTTO; RECH, 2016, p. 7).

Dois anos após a divulgação oficial da DCE-PR em 2008, ela sofreu uma modificação no nome. A partir do Parecer CEE/CEB número 130 de 2010, seu nome passou para Diretrizes Curriculares Orientadores da Educação Básica para a Rede Estadual de Ensino (DCOE-PR). Isso aconteceu devido ao fato de que já existiam, na época da sua construção, as Diretrizes Curriculares Nacionais da Educação Básica, e a mesma não pode ser maior do que a legislação federal estabelecida pelo Conselho Nacional. Segundo Paraná (2012), para continuar com a movimentação no sentido de implementar as DCOE-PR, foi lançado em 2012 o Caderno de Expectativas de Aprendizagem que visa subsidiar o "[...] trabalho docente, podendo ser utilizadas como referencial, tanto para o planejamento das aulas, quanto para o acompanhamento do trabalho pedagógico" (PARANÁ, 2012, p. $5)$.

Por fim, chega-se à última e mais atual mudança que está acontecendo nas políticas de currículos do país: a implementação da Base Nacional Comum Curricular - BNCC da Educação Infantil e Ensino Fundamental. A Base, à semelhança de outros documentos como por exemplo as DCOE-PR, não pretende ser um currículo, 
mas sim uma guia para professores, equipe pedagógica e gestores (em cada unidade da federação) na construção de seus currículos.

Nesse contexto, surgem indagações como: o fato de a BNCC não seguir declaradamente uma concepção filosófica pode mascarar as suas intenções; se os objetos de aprendizagem presentes na Geografia auxiliam o aluno a entender o espaço geográfico como objeto da Geografia; e se ela deixa claro as relações básicas da Geografia que são sociedade/natureza e espaço/tempo. Essas dúvidas deixam todos que trabalham com educação apreensivos, pois reformas educacionais ou curriculares realizadas no Brasil anteriormente sempre vieram acompanhadas de imposições e restrições, principalmente aos professores.

Visto isso, para complementar as discussões referentes a Geografia, é necessário discorrer sobre as finalidades educativas da disciplina, ou seja, sobre qual é a função da Geografia no contexto da formação global dos alunos. Por isso, a próxima seção vai trabalhar com a temática, trazendo a opinião dos autores da área em conjunto com as reflexões da autora.

\section{AS FINALIDADES DA GEOGRAFIA NO CURRÍCULO ESCOLAR}

Anteriormente já foi dito que a Geografia escolar foi tomando rumos diferentes no Brasil, de acordo com o contexto político e social que se tinha. As finalidades escolares da Geografia também foram sendo modificadas ao longo do tempo, desde uma busca de representação do nacionalismo patriótico no século XIX (VLACH, 1990), até o contexto mais atual, no qual segundo se pode depreender do exame da literatura, o pensamento espacial (pensar através dos conceitos geográficos) é enfatizado para compreender os fenômenos da atualidade (CALLAI, et al., 2016).

Para explicar melhor essa transição no ensino de Geografia, Vlach (1990, p. 45) esclarece que na Europa do século XIX era de fundamental importância fazer cada cidadão entender-se como patriota e valorizar o nacionalismo, e "[...] o ensino de Geografia contribuiu decisivamente nesse sentido, privilegiando a descrição do seu quadro natural”. A Geografia agregava, assim, o melhor escopo teórico-metodológico para amparar, de forma científica, a criação e o fortalecimento do sentimento nacionalista (CARVALHO, 2004). Sentimento esse que caminha com a compreensão do conceito de "país", o qual a Geografia buscava trabalhar seu aspecto territorial, tornando-o parte do imaginário coletivo (VESENTINI, 1994).

Além disso, nas palavras de Mormul (2018), os conhecimentos da Geografia também serviam para fins militares no fim do século XIX e início do século XX, pois a partir dela, era possível explorar diferentes territórios e conhecer seus potenciais e suas fragilidades. O controle dos territórios mostrava a soberania e o poder dos povos sobre os outros. 
Avançando algumas décadas no século XX, Cavalcanti (1998) salienta que o objetivo da Geografia aparece baseado predominantemente na transmissão de dados e informações gerais sobre o mundo, consubstanciando-se naquilo que comumente se denomina de Geografia tradicional. Foi a partir das críticas a esse ensino tradicional da Geografia que se começou a pensar e debater propostas alternativas e a realizar mudanças. As mudanças que daqui surgem, frente ao tipo de Geografia que se tinha até então e à definição de suas finalidades levam a consideráveis alterações no campo de ensino da mesma, até chegar a Geografia crítica ${ }^{3}$, na década de 1980.

Segundo Mormul (2018), a principal alteração na Geografia escolar iniciou com a inclusão de conteúdos que detinham uma perspectiva econômica e maior enfoque nas questões humanas. Além disso, as discussões passaram a ter um novo foco, que seria as relações entre sociedade, trabalho, natureza e produção do espaço geográfico. Esse movimento de renovação da Geografia buscou modificar as suas finalidades escolares, principalmente pelo fato de negar o papel de disciplina neutra e começar a fazer os alunos refletirem sobre o espaço geográfico em que vivem.

Nesse momento, é preciso ressaltar, como já afirmado, que a Geografia crítica avançou consideravelmente na renovação dos conteúdos e nas temáticas propostas para a sala de aula. Entretanto, ao mesmo tempo, não evoluiu suficientemente no aspecto metodológico do ensino dessa disciplina escolar. Isto é, ocorreu a renovação dos conteúdos que deveriam ser ministrados em sala, mas não houve avanço similar no campo da organização didática desses conteúdos, ou seja, na forma de ensinar.

É neste sentido que vemos se fortalecer na contemporaneidade ideias de que ensinar Geografia “[...] não é ensinar um conjunto de conteúdos e temas, mas é, antes de tudo, ensinar um modo de pensar, um modo de perceber a realidade, um modo de percebê-la espacialmente" (CALLAI, et al., 2016, p. 54). Têm-se, assim, o pressuposto de que esse modo específico de ver e de pensar, o "raciocínio geográfico", é uma importante ferramenta para o entendimento do mundo.

Cavalcanti (2006), em consonância com Castellar (2000), expõe a importância do raciocínio geográfico, afirmando que é necessário ao aluno aprender a pensar sobre o espaço e interpretá-lo porque as práticas sociais cotidianas possuem dimensão social. E é nas aulas de Geografia que ele terá os conhecimentos necessários para ter essa noção espacial.

Sobre isso, Cavalcanti (1998, p. 25) afirma que para os alunos realizarem uma leitura de mundo a partir das "lentes” da espacialidade, é necessário apropriação, por parte deles, “[...] de um conjunto de instrumentos conceituais de interpretação e de questionamento da realidade socioespacial". A Geografia deve oportunizar

\footnotetext{
${ }^{3}$ É importante dizer que outras correntes teóricas metodológicas também buscaram proporcionar modificações, mas a Geografia crítica foi aquela que, no contexto brasileiro, mais fortemente penetrou o ensino escolar.
} 
a construção de conceitos que ajudem o estudante a entender o seu presente e pensar no futuro com responsabilidade (STRAFORINI, 2004).

Isso quer dizer que a Geografia permite, fora do contexto da sala de aula, que o indivíduo planeje "[...] ações e reações sobre o espaço com o intuito de transformá-lo de acordo com suas necessidades ou interesses" (LOPES, 2010, p. 88). Carneiro (1993, p. 122) complementa que "[...] cabe à educação geográfica ocupar-se com a compreensão de mundo que o aluno vai elaborando a partir de sua experiência de espaço e lugar e da sua apreensão progressiva dos problemas de organização e uso do espaço pelo homem". A Geografia deve trabalhar com os alunos em todas as escalas, desde a local até a mundial. Porém, a sua realidade é o início da compreensão, é a escala local, que tem para o aluno o sentimento de pertencimento.

Entretanto, é necessário que se pense nesse espaço como algo em constante transformação, que está sempre sendo construído. Straforini (2004) afirma que ela é a única disciplina que viabiliza o acompanhamento das transformações no mundo de forma integrada. Oliveira (2010, p. 141) complementa dizendo que a disciplina "[...] procura desenvolver no aluno a capacidade de observar, analisar, interpretar e pensar criticamente a realidade tendo em vista a sua transformação". Isto é, a Geografia busca tornar o aluno um cidadão crítico e ativo na sociedade, desenvolvendo as habilidades descritas e utilizando os conceitos geográficos na análise da sua realidade. O mesmo autor ainda defende que o papel da Geografia é proporcionar a compreensão do espaço construído pela sociedade em que se vive hoje, suas contradições e desigualdades, as relações de produção que aqui são desenvolvidas e a apropriação que a sociedade faz com a natureza.

Além disso, a Geografia também se mostra importante na formação da consciência cidadã dos alunos, ela é um "[...] instrumento útil para ler e entender o mundo, para exercitar a cidadania e formar cidadãos" (CALLAI, 1999, p. 7).

Por fim, pode-se dizer que a formação e o desenvolvimento do pensamento espacial - o raciocínio geográfico - como meta a ser alcançada pela Geografia escolar se torna muito valioso aos alunos na medida que os ajuda a compreender diferentes fenômenos através da apropriação de seus conceitos-chave (paisagem, espaço, meio ambiente, lugar, natureza, território). Por isso, nesta perspectiva, o objetivo da Geografia não é apenas ensinar o rol de conceitos da disciplina, é também fazer os alunos refletirem sobre eles alcançando o raciocínio geográfico.

Em comparação com as outras perspectivas e finalidades que são atribuídas a Geografia, a ideia de lidar com ela como um modo de pensar é justamente a mesma que, como se verá no próximo tópico, aparece no componente curricular Geografia na BNCC. É esse pensamento que vai proporcionar a efetivação da educação 
geográfica, isto é, uma forma de ver o mundo a partir da Geografia, são as lentes do raciocínio geográfico que auxiliarão os alunos na compreensão dos fenômenos atuais.

\section{A BNCC: HISTÓRIA, PRINCÍPIOS E PRESSUPOSTOS}

A BNCC é um documento que vai nortear os diversos sistemas de ensino e, por consequência, os educadores no momento da elaboração e definição dos conteúdos que vão compor os currículos nos três níveis de ensino que compõem a Educação Básica. Para que fique claro a importância de um documento como a BNCC no cenário educacional, é necessário compreender a evolução dos fatos históricos que impulsionaram a sua criação, bem como os documentos que antecederam e embasaram sua concepção.

Seguindo, de forma cronológica, o primeiro documento brasileiro que traz a obrigatoriedade de uma base nacional comum é a Constituição Federal (CF) de 1988. Em seu Artigo 210 já preconizava a necessidade de fixar os "[...] conteúdos mínimos para o Ensino Fundamental, de maneira a assegurar formação básica comum e respeito aos valores culturais e artísticos, nacionais e regionais" (BRASIL, 1988, p.-, grifo nosso). Anos após a sua promulgação, mais precisamente em 1996, é divulgada a LDB 9.394 que traz em seu texto a obrigatoriedade de uma base nacional comum em todas as esferas da Educação Básica. Em seu Artigo 26 ela diz que "Os currículos da educação infantil, do ensino fundamental e do ensino médio devem ter base nacional comum, a ser complementada, em cada sistema de ensino e em cada estabelecimento escolar, por uma parte diversificada [...]" (BRASIL, 1996, p.-, grifo nosso).

A partir desses dois documentos de âmbito federal, surgiram, em diferentes estados da federação, diversas iniciativas curriculares baseadas na CF e na LDBEN. Em nível nacional, uma dessas iniciativas de grande destaque foram os Parâmetros Curriculares Nacionais (PCNs), elaborados e divulgados pelo MEC. Eles proporcionaram uma base para as diferentes esferas da educação: Parâmetros para a Educação Infantil, Ensino Fundamental e Ensino Médio, sendo cada um lançado em anos diferentes e cada disciplina contento o seu.

Avançando mais alguns anos, o evento e o documento mais significativos para a educação e a criação da BNCC são a Conferência Nacional de Educação (CONAE) e o Plano Nacional de Educação (PNE). De acordo com Fernandes (2012), o governo federal, juntamente com a sociedade civil, realizou conferências em várias áreas, tendo destaque para a área de educação, como é o caso da CONAE de 2010. Essa conferência teve como resultado um processo de discussão e mobilização, que proporcionou a apresentação de metas, ações e diretrizes para a política nacional de educação, no ponto de vista da diversidade, igualdade e inclusão, que se mostrou como balizadora para a educação brasileira na atualidade (CONAE, 2010).

Antes dela houve outras conferências nas esferas municipal, estadual e distrital, cumprindo relevante papel na aprovação de concepções para a área educacional. Essas reuniões, de acordo com Fernandes (2012), 
proporcionaram a estruturação do PNE 2001-2010 a partir de eixos temáticos. O PNE que está em vigência atualmente abrange os anos de 2014 a 2024. É composto de 20 metas e 10 diretrizes que envolvem desde a erradicação do analfabetismo e melhora na qualidade da educação, até a valorização dos profissionais da educação (BRASIL, 2014).

Em suma, pode-se dizer que a LDBEN (1996), as DCNs (2009) e o PNE (2014) mostraram a exigência, imposta ao sistema educacional brasileiro, de uma Base Nacional Comum Curricular. Base essa que faz parte das reformas educacionais que se iniciaram na década de 1990. De acordo com Libâneo, Oliveira e Toschi (2012), as transformações sociais que ocorreram no mundo na década de 1980 só foram chegar ao Brasil na próxima década com o governo de Fernando Collor (1990-1992).

Dessa forma, pode-se dizer que a ideia de criação de uma base nacional não é recente, já vem acontecendo desde a Constituição Federal, sendo que esse processo só foi ter início, de fato, no ano de 2015, quando veio à público a Primeira Versão da Base. O documento passou por mais algumas versões até que a Versão Definitiva, ou Versão Final, da Educação Infantil e Ensino Fundamental (El/EF) foi aprovada e homologada em dezembro de 2017 e a do Ensino Médio foi aprovada e homologada em dezembro de 2018.

\section{O COMPONENTE CURRICULAR GEOGRAFIA NA BNCC}

A Geografia é encontrada na BNCC como um dos componentes curriculares pertencentes a área de Ciências Humanas. $O$ texto introdutório da área traz algumas informações genéricas, conceitos específicos das quatro ciências contempladas na área e o que deve ser valorizado no Ensino Fundamental Anos Iniciais e Finais. Além disso também busca apresentar as competências gerais das Ciências Humanas. E o texto que apresenta o componente curricular Geografia segue o mesmo formato, mas, além disso, também expõe alguns princípios do raciocínio geográfico.

Para iniciar a análise do texto referente à Geografia, é importante dizer, inicialmente, que ele não se filia explicitamente à uma determinada corrente do pensamento geográfico, nem se preocupa em relacionar a história da ciência de referência à disciplina escolar. Assim, o tradicional resgate da história da ciência, suas diferentes abordagens teórico-metodológicas e seus impactos ao longo da história na disciplina escolar não são destacados.

Destarte, o texto da BNCC não faz a defesa explícita de uma determinada concepção ou orientação teórica da Geografia. Afirma inicialmente, ao apresentar esse componente curricular, que o estudo da Geografia é uma oportunidade para se compreender o mundo em que se vive, na medida em que "[...] aborda as ações humanas construídas nas distintas sociedades existentes nas diversas regiões do planeta" (BRASIL, 2017, p. 357). O documento evidencia, ao mesmo tempo, que a educação geográfica contribui para a formação 
do conceito de identidade salientando, entre outros fatores, a importância de se considerar que os seres humanos são "sujeitos da história", mas "distintos uns dos outros" (p. 357) e, por isso, "convictos das nossas diferenças" (p. 357).

Assim, buscando explicitar a especificidade do componente curricular Geografia, o documento afirma que "Para fazer a leitura do mundo em que vivem, com base nas aprendizagens em Geografia, os alunos precisam ser estimulados a pensar espacialmente, desenvolvendo o raciocínio geográfico" (BRASIL, 2017, p. 357, grifos nossos). Ao justificar a valorização da capacidade dos jovens de pensar espacialmente por meio do raciocínio geográfico, o documento informa que esta concepção é compartilhada por propostas curriculares de diversos países tais como o Reino Unido, Portugal, Estados Unidos da América, Chile e Austrália.

O texto afirma que o pensamento espacial "[...] está associado ao desenvolvimento intelectual que integra conhecimentos não somente da Geografia, mas também de outras áreas (como Matemática, Ciência, Arte e Literatura)" (BRASIL, 2017, p. 357). Assim, por um lado, o documento afirma a especificidade do modo de compreender o mundo do ponto de vista da Geografia e, por outro lado, indica que tal processo está implicado em conhecimentos de outras disciplinas ou áreas.

\section{O RACIOCÍNIO GEOGRÁFICO}

O texto da BNCC, de certo modo, reverbera uma ideia que tem se fortalecido recentemente de que o ensino de Geografia deve promover ao aluno a oportunidade de se apropriar de um modo específico de olhar e compreender o mundo: o olhar geográfico (LOPES, 2010; CALLAI, et al., 2016; CAVALCANTI, 2010). Isso faz com que no centro dos objetivos do ensino de Geografia, ou da educação geográfica, esteja o desenvolvimento do raciocínio geográfico. Ele é definido como uma maneira de exercitar o pensamento espacial a partir da aplicação de determinados princípios “[...] para compreender aspectos fundamentais da realidade: a localização e a distribuição dos fatos e fenômenos na superfície terrestre, o ordenamento territorial, as conexões existentes entre componentes físico-naturais e as ações antrópicas" (BRASIL, 2017, p. 357). Como afirma explicitamente o documento:

\footnotetext{
Essa é a grande contribuição da Geografia aos alunos da Educação Básica: desenvolver o pensamento espacial, estimulando o raciocínio geográfico para representar e interpretar o mundo em permanente transformação e relacionando componentes da sociedade e da natureza. Para tanto, é necessário assegurar a apropriação de conceitos para o domínio do conhecimento fatual (com destaque para os acontecimentos que podem ser observados e localizados no tempo e no espaço) e para o exercício da cidadania (BRASIL, 2017, p. 358, grifos nossos).
}

A centralidade dada ao pensamento espacial e ao exercício do raciocínio geográfico parece ser, simultaneamente, o ponto forte e ponto fraco do documento. De fato, o debate em torno do significado que 
se pode atribuir ao raciocínio geográfico é recente na Geografia e parece que é uma preocupação maior dos pesquisadores do ensino de Geografia em sua tentativa de caracterizar os significados de "Educação Geográfica" do que propriamente da pesquisa no campo da epistemologia da Geografia.

Ao repercutir as pesquisas que no campo da Geografia enfatizam essa questão, o documento pode contribuir efetivamente para o avanço do conhecimento geográfico. Entretanto, não se pode mostrar em poucos parágrafos seu sentido mais profundo. Assim, considerando que todos os documentos dessa natureza sofrem, necessariamente, nas diferentes instâncias, uma interpretação é preocupante. Assim, a superficialidade de sua apresentação poderia incorrer em erros e distorções e, em consequência, retrocessos.

No texto do documento a compreensão do raciocínio geográfico aparece articulado à possibilidade do aluno de se apropriar e de mobilizar em suas aprendizagens os conceitos geográficos. Essa visão é reforçada no documento inclusive nas competências específicas de Geografia para o Ensino Fundamental. Nesse texto, é possível identificar que elas focam no desenvolvimento do raciocínio geográfico e do pensamento espacial, auxiliando os alunos na sua formação global. Além disso, é citado a importância em se desenvolver nos estudantes a consciência ambiental, que faz parte também da formação da Geografia escolar.

Ainda no texto das competências, nota-se expressões relacionadas ao mundo do trabalho como "resiliência", "resolução de problemas", "flexibilidade", "senso crítico" e "protagonismo". Expressões essas que Libâneo, Oliveira e Toschi (2012) descrevem como necessárias ao ensino escolar atual na perspectiva do neoliberalismo.

A sétima competência, específica da Geografia, coincide com a décima competência geral da Base, a qual ressalta que os alunos devem agir com base em princípios "[...] éticos, democráticos, sustentáveis e solidários" (BRASIL, 2017, p. 364). Quando é procurado na redação do documento o significado dos quatro vocábulos, mais uma vez, não são encontrados. Isso é um problema recorrente no texto da BNCC, traz-se diversas palavras que podem vir carregadas de intenções ou até mesmo fornecer interpretações diferentes, mas não é esclarecido seu conceito, deixando em dúvida o leitor.

A partir dessa reflexão é possível dizer que o raciocínio geográfico (forma de pensar) é um ponto forte da Geografia, que auxilia na formação global dos alunos, e deve ser trabalhado quando se fala na Geografia escolar. Por isso, o próximo subitem cuidará de explicitar como os conceitos da disciplina são utilizados no documento, pois é através deles que haverá a formação do raciocínio geográfico. 


\section{O EXERCÍCIO DO RACIOCÍNIO GEOGRÁFICO POR MEIO DA MOBILIZAÇÃO DOS CONCEITOS}

Compreende-se, pela leitura e imersão no texto da BNCC, que o exercício do raciocínio geográfico e desenvolvimento do pensamento espacial, se faz via mobilização de conceitos geográficos e da aplicação de procedimentos de pesquisa e análise próprios dessa área de conhecimento. A compreensão dos conceitos geográficos envolve não somente o seu significado, mas também a sua aplicação na realidade. Sua assimilação permite ao aluno o desenvolvimento de uma nova visão de mundo, uma visão que conta com o raciocínio geográfico para entender os fenômenos da realidade de forma crítica e ativa.

Essa ideia de uma nova visão de mundo que o documento traz está de acordo com o pensamento de Young $(2016,2011,2007)$. A concepção de que os alunos devem ter acesso ao "conhecimento poderoso", na escola, está relacionado à nova perspectiva de mundo que a BNCC coloca dentro do componente curricular Geografia. Os alunos devem ir à escola para obterem um conhecimento novo, algo que não encontrariam no simples contato com a realidade cotidiana. Atingir a perspectiva do pensamento espacial, embasada no raciocínio geográfico que o documento coloca, seria chegar as formas mais elevadas de pensamento descritas por Vygotsky (1993). Isso resulta na apropriação do conhecimento científico propriamente dito.

Nesse sentido, a BNCC descreve quais são os conceitos geográficos que considera mais relevantes para constar nos currículos e proporcionar o desenvolvimento, pelos alunos, do pensamento espacial.

[...] a BNCC está organizada com base nos principais conceitos da Geografia contemporânea, diferenciados por níveis de complexidade. Embora o espaço seja o conceito mais amplo e complexo da Geografia, é necessário que os alunos dominem outros conceitos mais operacionais e que expressam aspectos diferentes do espaço geográfico: território, lugar, região, natureza e paisagem (BRASIL, 2017, p. 359).

O espaço constitui-se, assim, no conceito mais amplo e complexo a ser compreendido, desenvolvido e mobilizado pelos alunos ao longo do Ensino Fundamental. Entretanto, a compreensão deste é mediada por outros, definidos como "mais operacionais" (território, lugar, região, natureza, paisagem), referindo-se, provavelmente, aos conceitos mais práticos ou menos abstratos da Geografia (BRASIL, 2017, p. 359), ou seja, mais acessíveis aos alunos do Ensino Fundamental. $O$ texto não explicita as relações existentes entre eles (entre o espaço e o território, lugar, região, natureza e paisagem) e não esclarece ou aprofunda a natureza "mais operacional" dos cinco últimos.

Além dos conceitos que a Base traz em seu texto, também pode-se encontrar um quadro que descreve sete princípios do raciocínio geográfico. Ou seja, o documento procura articular os princípios que professores podem utilizar para conduzir os alunos a pensarem da forma que o raciocínio geográfico propõe. Esses princípios são os seguintes: analogia, conexão, diferenciação, distribuição, extensão, localização e ordem. 
Cada um dos princípios apontados pode ser entendido como recursos a serem empregados dentro de sala de aula pelos professores. A analogia ajuda a "aproximar" fenômenos geográficos que se assemelham e acontecem em locais diferentes, ajuda a fazer comparações e buscar características parecidas. Nesse mesmo contexto, é possível fazer uma conexão entre os fenômenos, isto é, entender o que é semelhante e de que forma eles se conectam. Ademais, utilizando a ideia de diferenciação, é possível compreender as suas particularidades. Moreira (1999, p. 47) explica melhor o conceito mostrando que "diferença" e "semelhança" não são sinônimos e como a "diferença" é entendida dentro da Geografia:

\begin{abstract}
Diferença e semelhança não são pois opostos entre si. E diferenças não são contrastes. Diferença é variação. É a variação de uma mesma categoria de fenômeno na superfície terrestre (o clima, por exemplo) que conduz à diferenciação de áreas (variação do mesmo? diferenciação no sentido do que produz diferença?), enfatiza Hartshorne. E é esse caráter de variação de um mesmo fenômeno, dando na diferenciação de áreas, o que distingue a geografia de "um catálogo organizado ou uma enciclopédia de fatos sobre diversos países", errando pois quem acha que a geografia se limita a "distinguir área", a "estabelecer diferenças entre uma e outra área" ou a fazer a "mera descrição de uma área", uma vez que diferenciação é variação, e essa variação pela superfície terrestre é por excelência o tema geográfico.
\end{abstract}

Já o princípio da distribuição está conectado diretamente a ocupação do espaço geográfico, mesmo que isso não esteja explicitamente descrito no documento. A forma como os fenômenos se distribui no mundo e seus "porquês" auxiliam a definir o espaço. Entretanto, para que essa definição aconteça, é necessário que se entenda o tamanho do fenômeno e até onde ele atinge. Para isso, a concepção de extensão contribui no sentido de fazer o aluno pensar no espaço geográfico a partir de outro viés, lembrando-o de que os fenômenos possuem limites.

Os dois últimos princípios são localização e ordem. A localização está intimamente ligada com a noção de identificação e de lugar, as quais o sentimento de pertencimento e de relações sociais é necessário para existirem. Todavia, ela também se relaciona com o local, que pode ser definido a partir de localizações exatas como as coordenadas geográficas, por exemplo. Por fim, a ordem busca complementar a localização, pois a primeira trata da ocupação do espaço e a segunda do ordenamento territorial. O princípio da ordem almeja trabalhar com a estruturação do espaço geográfico, com o seu uso e como a política, a sociedade e o planejamento territorial podem interferir nessa concepção.

Outro aspecto, associado ao uso adequado dos conceitos geográficos, destacado pelo texto - mas insuficientemente desenvolvido - é a ideia de que é preciso superar as aprendizagens baseadas na descrição de informações e fatos do dia a dia dos sujeitos.

A ultrapassagem dessa condição meramente descritiva exige o domínio de conceitos e generalizações. Estes permitem novas formas de ver o mundo e de compreender, de maneira ampla e crítica, as múltiplas relações que conformam a realidade, de acordo com o aprendizado do conhecimento da ciência geográfica (BRASIL, 2017, p. 359). 
O processo de superação do contexto mais imediato da vida dos sujeitos e a apropriação da visão da ciência medida pelos conceitos geográficos, via processo de generalização, é algo, portanto, interessante, mas que no texto é insuficientemente desenvolvido. Fato que pode muito mais confundir do que propriamente orientar.

\section{AS UNIDADES TEMÁTICAS}

Ao propor que os conteúdos de aprendizagem e respectivas habilidades de cada componente curricular estejam agrupados no interior de unidades temáticas, o documento salienta que a adoção de tal procedimento busca respeitar as muitas possibilidades de organização do conhecimento escolar, defendendo, também, que as unidades temáticas devem definir "[...] um arranjo dos objetos de conhecimento ao longo do Ensino Fundamental adequado às especificidades dos diferentes componentes curriculares" (BRASIL, 2017, p. 29).

Entende-se, portanto, que as unidades temáticas expressam, em conjunto, a lógica científica das disciplinas escolares e busca alcançar seus objetivos, vale dizer, suas finalidades fundamentais. "Cada unidade temática contempla uma gama maior ou menor de objetos de conhecimento, assim como cada objeto de conhecimento se relaciona a um número variável de habilidades [...]" (BRASIL, 2017, p. 29).

As unidades temáticas correspondem a partes comuns em todo o Ensino Fundamental. Elas são dotadas de habilidades que possuem continuidade e progressão nas suas etapas, ou seja, embora se repitam em todas as séries, os objetos de conhecimentos ${ }^{4}$ e habilidades que os compõem devem apresentar níveis crescentes de complexidade da compreensão conceitual a respeito da produção do espaço.

Encontramos aqui uma questão importante insistentemente destacada pelas pesquisas que enfatizam o ensino da Geografia nos Anos Iniciais do Ensino Fundamental que indicam, de modo geral, deficiências na formação geográfica do pedagogo (LEMES, 2016). Essas deficiências estão relacionadas à formação que os pedagogos recebem no Ensino Superior. Muitas vezes, as disciplinas do currículo pertencentes à área de Geografia, assim como a carga horária que recebem, não é suficiente para dar conta da complexidade que os conceitos geográficos requerem. Isso pode fazer com que os professores deem mais espaço para o componente curricular que tem mais afinidade ou até mesmo para o componente que lhes foi dado melhor formação no Ensino Superior.

Em consequência, os alunos do Ensino Fundamental Anos Iniciais chegam, geralmente, aos Anos Finais sem os requisitos necessários à aprendizagem geográfica. A afirmação desse princípio - de continuidade e progressão - na BNCC está implicada na revisão da formação de professores para esse nível de ensino e um

\footnotetext{
${ }^{4}$ Entendidos, conforme compreensão do documento como conteúdos, conceitos e processos (BRASIL, 2017).
} 
maior aprofundamento teórico conceitual nas diferentes áreas do currículo. Esse aprofundamento se faz fundamental porque os pedagogos em formação precisam estar munidos da complexidade dos conceitos geográficos para trabalhá-los da melhor forma no Ensino Fundamental.

Quanto à distribuição dos objetos de conhecimentos pelos anos que compõem o Ensino Fundamental Anos Finais (o sexto, o sétimo, o oitavo e nono anos) e as habilidades a eles relacionadas, observa-se que, a despeito da novidade de agrupá-los no interior de unidades temáticas, esta segue um modelo tradicionalmente presente em grande parte dos livros didáticos utilizados no país tal qual se pode observar a seguir no Quadro 1.

Quadro 1. Organização dos conteúdos trabalhados no Ensino Fundamental Anos Finais. Fonte: BRASIL (2017). Organização: a autora

\begin{tabular}{|c|c|c|c|c|}
\hline Ano & 60 ano & 70 ano & 80 ano & 90 ano \\
\hline Habilidades & $\begin{array}{l}\text { - Análise da transformação } \\
\text { das paisagens; } \\
\text { - Interação da sociedade } \\
\text { com a natureza; } \\
\text { - Modificação das } \\
\text { paisagens urbanas e rurais; } \\
\text { - Relação campo versus } \\
\text { cidade; } \\
\text { - Recursos naturais, sua } \\
\text { exploração e degradação } \\
\text { pelo ser humano; } \\
\text { - Escala gráfica e numérica. }\end{array}$ & $\begin{array}{l}\text { - Ocupação e } \\
\text { povoamento do } \\
\text { território brasileiro; } \\
\text { - Formação das divisas } \\
\text { do território brasileiro; } \\
\text { - Tipos de } \\
\text { regionalização } \\
\text { brasileira; } \\
\text { - Características físicas, } \\
\text { sociais e econômicas } \\
\text { das regiões do Brasil; } \\
\text { - Importância das } \\
\text { áreas de proteção } \\
\text { ambiental e } \\
\text { preservação dos } \\
\text { recursos naturais; } \\
\text { - Características dos } \\
\text { setores da economia } \\
\text { brasileiros. }\end{array}$ & $\begin{array}{l}\text { - Regionalizações } \\
\text { mundiais; } \\
\text { - Configuração das } \\
\text { fronteiras do } \\
\text { continente americano e } \\
\text { africano; } \\
\text { - Características físicas, } \\
\text { demográficas, } \\
\text { econômicas e sociais da } \\
\text { América e da África; } \\
\text { - Os blocos econômicos } \\
\text { e suas relações } \\
\text { políticas; } \\
\text { - Introdução a } \\
\text { globalização: circulação } \\
\text { de capital, mão-de-obra } \\
\text { e mercadorias no } \\
\text { mundo; } \\
\text { - Os tipos de migração, } \\
\text { as migrações do } \\
\text { território brasileiro e do } \\
\text { mundo; } \\
\text { - A Antártica, seu } \\
\text { contexto político e } \\
\text { importância mundial. }\end{array}$ & $\begin{array}{l}\text { - A nova ordem } \\
\text { mundial; } \\
\text { - A fase atual da } \\
\text { revolução industrial } \\
\text { e os espaços de } \\
\text { produção; } \\
\text { - Características } \\
\text { físicas, } \\
\text { demográficas e } \\
\text { sociais da Oceania, } \\
\text { Europa e Ásia; } \\
\text { - Comércio mundial; } \\
\text { - A formação das } \\
\text { fronteiras mundiais } \\
\text { e a reconfiguração } \\
\text { do território; } \\
\text { - A transformação } \\
\text { demográfica } \\
\text { mundial; } \\
\text { - Globalização e as } \\
\text { culturas } \\
\text { diversas das } \\
\text { sociedades; } \\
\text { - A dinâmica das } \\
\text { redes na atual } \\
\text { configuração dos } \\
\text { territórios. }\end{array}$ \\
\hline
\end{tabular}

O Quadro 1 expõe, de forma sucinta, os conteúdos de Geografia que estão descritos dentro das habilidades do componente curricular Geografia. De forma geral, a Base aborda os mesmos conteúdos que já são normalmente trabalhados em sala de aula pelos professores. Entretanto, podem-se identificar algumas mudanças: no sétimo ano, a autora sentiu falta dos movimentos sociais que se realizam no campo; no oitavo ano, o documento propõe o estudo da Antártica (que geralmente é realizada no nono ano) e não menciona o Ártico; no nono ano, a exposição das habilidades está semelhante ao que já acontece atualmente. 
É válido ressaltar que o documento da ênfase à cinco conceitos geográficos operacionais, mas ao longo dos quatro anos do Ensino Fundamental Anos Finais não menciona, suficientemente, nada sobre trabalhar especificamente com algum desses conceitos ou até mesmo com o conceito de espaço geográfico, objeto de estudo da Geografia. Isso mostra uma contradição do documento, pois ao mesmo tempo que chama a atenção para os conceitos chave da disciplina no texto introdutório, não frisa razoavelmente sua utilização como conceito no desenvolvimento das habilidades.

De forma geral, a estruturação dos conteúdos da Base, mostrados no Quadro 1, expõe o que deve ser trabalhado nesse nível da Educação Básica. Entretanto, não se pode esquecer que eles ganharão formatos diferenciados de acordo com a região do país ou até mesmo com o próprio planejamento de cada escola. É nesse momento que os professores podem participar ativamente do processo de construção dos currículos em suas escolas, ajudando a selecionar os conteúdos, além dos que já estão na BNCC, que entendem serem relevantes para o seu componente curricular, região e alunos.

\section{CONCLUSÃO}

Através da investigação realizada neste artigo, foi possível identificar os documentos que mostravam a necessidade de criar uma base comum para o país, entender como aconteceu esse processo, sempre dando ênfase ao componente curricular Geografia.

O objetivo principal da pesquisa foi analisar, considerando seus fundamentos e intenções, o processo histórico de construção da Base Nacional Comum Curricular, particularmente do componente curricular Geografia e seus possíveis impactos no processo ensino-aprendizagem e na formação do professor. Para que se chegasse à consecução dos objetivos, foi necessário executar uma busca de referencial teórico que trabalhasse com o contexto da Geografia escolar no Brasil, os objetivos, finalidades e relevância da disciplina dentro da Educação Básica.

A Base deixa claro, desde suas primeiras páginas, que pretende ser um documento plural e contemporâneo que alcance os alunos brasileiros de todas as regiões e, nesse sentido, conseguiu cumprir o que propôs. A parte destinada a Geografia não exprime claramente ou filia-se a nenhuma das correntes teóricas pertencentes a história da Geografia. Assim sendo, ela segue a ideia geral da Base que é ser plural.

O documento trata a Geografia como disciplina que auxilia a formação global dos alunos, ponto que pode ser considerado positivo. O argumento utilizado pela BNCC para justificar tal afirmação é que sua contribuição para a formação cidadã dos alunos e, consequentemente, para a interpretação e transformação da realidade, se faz via desenvolvimento do pensamento espacial e estímulo do raciocínio geográfico. Esse 
fato expõe, como apresentado ao longo do texto, a ideia expressa por Callai et al. (2016), que a Geografia proporciona aos alunos um modo de pensar e perceber a realidade espacialmente.

O texto da BNCC reverbera, portanto, o entendimento presente em parte da pesquisa que foca o ensino na atualidade (CALLAI et al., 2016; CAVALCANTI, 2006; LOPES, 2010) e o campo da epistemologia da Geografia (GOMES, 2017; MOREIRA, 1999), de que a finalidade maior da educação geográfica no currículo escolar é ensinar um modo particular de pensar. Ou seja, é antes de tudo, proporcionar ao aluno que ele perceba e compreenda a realidade espacialmente.

Essa iniciativa do documento é considerada promissora, mas observou-se que a relação existente entre a mobilização de conceitos e procedimentos com o desenvolvimento do raciocínio geográfico pelo aluno é insuficientemente desenvolvida no texto. Além disso, o fato de a BNCC não aprofundar o significado dos conceitos pertinentes à disciplina, bem como a relação existente entre eles - visto tratar-se de um documento cheio de intenções - deixa uma evidente lacuna.

Evidencia-se, assim, a importância da ação dos pesquisadores da área na discussão da temática e apresentação de subsídios nos quais os professores possam se apoiar para a interpretação e efetiva implementação da Base. Nesse sentido, é importante que os professores não fiquem em segundo plano na elaboração dos currículos, eles devem ser também os "arquitetos" em conjunto com a equipe pedagógica.

Outra lacuna identificada no texto da BNCC, e que toca particularmente a disciplina de Geografia, é a escassa referência ao trabalho de campo ou ao estudo do meio no trabalho pedagógico dessa disciplina (citado apenas duas vezes, sendo uma delas na introdução da área de Ciências Humanas e outra na área de Geografia que trata do Ensino Fundamental Anos Iniciais). Entende-se que a observação direta do espaço geográfico, a excursão, o trabalho de observação e a análise da paisagem representam uma rica tradição escolar e científica e é um dos marcos identitários dessa disciplina escolar.

Outro ponto constatado no documento foi seu alinhamento com as políticas educacionais propostas ou financiadas pelas organizações internacionais. Essas políticas têm como finalidade, dentre outros fatores, a formação de alunos para o mercado de trabalho, e não propriamente para o pleno desenvolvimento de suas potencialidades humanas. Isto é, o foco principal do Ensino Fundamental e Médio é o ensino de habilidades e competências necessárias para o trabalho. Exatamente isso é o que acontece na BNCC EI/EF, há a valorização de vários tipos de habilidades e competências que são características do mundo do trabalho, aparecendo diversas vezes dentro do documento, tanto das competências da parte geral como das competências específicas da Geografia.

Por esse motivo, é possível afirmar que a Base também reflete, de modo geral, princípios neoliberais para a educação no século XXI. Esses princípios estão voltados, como já foi visto, à preparação dos alunos para 
o mercado de trabalho a partir do desenvolvimento de algumas habilidades e competências específicas descritas em documentos formulados por organizações internacionais como FMI e UNESCO, por exemplo. Características essas que foram identificadas dentro da BNCC por meio de palavras e expressões como: solidariedade, ética, resiliência, consciência ambiental, senso crítico, autonomia e justiça.

Por fim, deve haver também uma preocupação maior com a formação geográfica do pedagogo. É necessário que eles consigam um aprofundamento e progressão dos conteúdos dentro da sua formação, pois precisam estar munidos da complexidade dos conceitos geográficos para trabalhá-los da melhor forma no Ensino Fundamental Anos Iniciais. Essa perspectiva baseada na progressão de conteúdos não é nova ao universo educacional brasileiro, mas deve existir uma atenção especial, principalmente no que tange à formação geográfica do pedagogo.

Depois de respondidas as questões pertinentes a pesquisa, levando em conta a importância do documento para o país e analisando os contextos pertinentes a sua compreensão, é possível afirmar que a BNCC oferecerá maior uniformidade aos currículos brasileiros a partir da definição dos conteúdos que deverão ser ensinados em todas as regiões do país. A tentativa de aproximar os currículos do Brasil é inicialmente válida, pois acontecerá ao mesmo tempo e supostamente com os mesmos conteúdos, auxiliando os professores no momento do planejamento de seus conteúdos ao longo do ano. Porém, se não houver formação inicial e formação continuada ${ }^{5}$ para eles, mais reflexões e debates a respeito da implantação e utilização da BNCC na elaboração dos currículos do Brasil, o documento poderá não atingir seu objetivo de unificar o ensino no país.

\section{REFERÊNCIAS}

ALBUQUERQUE, Maria Adailza Martins de. Dois momentos na história da Geografia escolar: a Geografia clássica e as contribuições de Delgado de Carvalho. Rev. Bras. Educ. Geog., Rio de Janeiro, v. 1, n. 2, p. 19-51, jul.-dez. 2011.

BRASIL. Decreto de 2 de dezembro de 1837. Convertendo o Seminnrio de S. Joaquim em collegio de instrucção secundaria, com a denominação de Collegio de Pedro II, e outras disposições. 1837. Disponível em:

<http://www.cp2.g12.br/images/comunicacao/2015/historia_cp2/colleccao_leis_1837_parte2.66-68.pdf> Acesso em: 4 de abr. de 2019.

Secretaria de Educação Fundamental. Parâmetros curriculares nacionais: introdução aos parâmetros curriculares nacionais. Brasília: MEC/SEF, 1997.

. Constituição (1988). Constituição da República Federativa do Brasil. Brasília: Senado Federal, 1988. Disponível em: <http://www.planalto.gov.br/ccivil_03/constituicao/constituicaocompilado.htm> Acesso em: 11 de jun. de 2019.

. Lei de Diretrizes e Bases da Educação Nacional no 9.394 de 20 de dezembro de 1996. Disponível em: <http://www.planalto.gov.br/Ccivil_03/leis/L9394.htm> Acesso em: 11 de jun. de 2018.

\footnotetext{
${ }^{5}$ O governo lançou um documento preliminar em dezembro de 2018 intitulado "Proposta para Base Nacional Comum da Formação de Professores da Educação Básica" que visa orientar uma mesma linguagem para formação inicial e continuada de professores.
} 
Plano Nacional de Educação 2014-2024: Lei no 13.005, de 25 de junho de 2014, que aprova o Plano Nacional de Educação (PNE) e dá outras providências. - Brasília: Câmara dos Deputados, Edições Câmara, 2014.

Ministério da Educação. Base Nacional Comum Curricular: Versão Final. Brasília: MEC, 2017. Disponível em: <http://basenacionalcomum.mec.gov.br/a-base> Acesso em: 22 de mai. de 2019.

CACETE, Núria Hanglei. Reforma educacional em questão: os parâmetros curriculares nacionais para o ensino de geografia e a formação de professores para a escola básica. In: ALBUQUERQUE, Maria Adailza Martins de.; FERREIRA, Joseane Abílio de Souza. (Orgs.) Formação, pesquisa e práticas docentes: reformas curriculares em questão. João Pessoa: Mídia, 2013. p. 47-58.

CALLAI, Helena Copetti. et al. O ensino de Geografia nos trabalhos apresentados no XI ENANPEGE. Revista da ANPEGE, v. 12, n. 18, p. 43-55. 2016. Disponível em: <http://ojs.ufgd.edu.br/index.php/anpege/issue/view/259/showToc>Acesso em: 12 de nov. de 2018.

. Aprendendo a ler o mundo: a Geografia nos anos iniciais do ensino fundamental. Cad. Cedes, Campinas, v. 25, n. 66, p. 227$247,2005$.

. O ensino de Geografia: recortes espaciais para análise. In: CASTROGIOVANNI, Antonio Carlos. (Org.) Geografia em sala de aula: práticas e reflexões. Porto Alegre: AGB, Seção Porto Alegre, 1998.

A Geografia no Ensino Médio. Terra Livre - As Transformações do Mundo da Educação - Geografia, Ensino e Responsabilidade Social, São Paulo: Associação dos Geógrafos Brasileiros, n. 14, p. 56-89, jan.-jul. 1999.

CARNEIRO, Sônia Maria Marchiorato. Importância educacional da geografia. Educar, Curitiba, n. 9, p. 121-125. 1993.

CARVALHO, Maria Inez. Fim de século: a escola e a geografia. 2ae ed. ljuí: Ed. Unijuí, 2004.

CASTELLAR, Sônia Maria Vanzela. A alfabetização em geografia. Espaços da Escola, ljuí, v. 10, n. 37, p. 29-46, jul.-set. 2000.

CAVALCANTI, Lana de Souza. Geografia, escola e construção de conhecimento. Campinas: Papirus, 1998.

Bases teórico-metodológicas da Geografia: uma referência para a formação e a prática de ensino. In: CAVALCANTI, Lana de Souza. (Org.) Formação de professores: concepções e práticas em Geografia. Goiânia: Vieira, 2006. p. 27-49.

CAVALCANTI, L. de S. A geografia e a realidade escolar contemporânea: avanços, caminhos, alternativas. In: Anais do I seminário nacional: currículo em movimento - Perspectivas Atuais Belo Horizonte, nov. 2010. Disponível em:

<http://portal.mec.gov.br/docman/dezembro-2010-pdf/7167-3-3-geografia-realidade-escolar-lana-souza/file>. Acesso em: 24 de out. de 2018.

CONFERÊNCIA NACIONAL DE EDUCAÇÃO (CONAE), 2010, Brasília, DF. Construindo o Sistema Nacional articulado de Educação: o Plano Nacional de Educação, diretrizes e estratégias. Documento Final. Brasília: MEC, 2010. Disponível em:

<http://conae.mec.gov.br/images/stories/pdf/pdf/documetos/documento_final.pdf> Acesso em: 12 de jun. de 2019.

FERNADES, Francisco das Chagas. A Conae, o PNE e as condições de trabalho. Revista Retratos da Escola, Brasília, v. 6, n. 11, p. 327338, jul.-dez. 2012.

GIROTTO, Eduardo Donizeti.; RECH, Roberto Carlos. Educação e Geografia em Élisée Reclus: presença e ausência nas diretrizes curriculares de Geografia do Paraná. Terra Brasilis (Nova Série), São Paulo, n. 7, p. 1-13, 2016.

JACOMELI, Mara Regina Martins. A Lei 5.692 de 1971 e a presença dos preceitos liberais e escolanovistas: os estudos sociais e a formação da cidadania. Revista HISTEDBR On-line, Campinas, n. 39, p. 76-90, set. 2011.

LEMES, R. de O. Necessidades formativas em geografia para professores dos anos iniciais do ensino fundamental. $158 \mathrm{f}$. Dissertação (Mestrado em Geografia) - Centro de Ciências Humanas, Letras e Arte. Universidade Estadual de Maringá, Maringá, 2016.

LIBÂNEO, José Carlos.; OLIVEIRA, João Ferreira de.; TOSCHI, Mirza Seabra. Educação escolar; políticas estrutura e organização. 10 ed. São Paulo: Cortez, 2012.

LOPES, Claudivan Sanches. O professor de Geografia e os saberes profissionais: o processo formativo e o desenvolvimento da profissionalidade. 2010. 258 f. Tese (Doutorado) Faculdade de Filosofia, Letras e Ciências Humanas, Universidade de São Paulo, São Paulo, 2010.

MOREIRA, Ruy. A diferença e a Geografia: o ardil da identidade e a representação da diferença na geografia. GEOgraphia, Rio de Janeiro, ano 1, n. 1, p. 41-58, 1999.

MORMUL, Najla Mehanna. Escola e Geografia para quem? In: I SENACORPUS - Seminário Corpos Possíveis do Brasil Profundo, v. 1, Rio Grande, 2018. Anais SENACORPUS. Disponível em: <http://www.editorarealize.com.br/revistas/senacorpus/anais.php> 
Acesso em: 7 de jun. de 2019.

OLIVEIRA, Ariovaldo Umbelino de. Educação e ensino de Geografia na realidade brasileira. In: OLIVEIRA, Ariovaldo Umbelino de. Para onde vai o ensino de geografia? (Org.) 9 ed. São Paulo: Contexto: 2010.

PARANÁ. Secretaria de Estado da Educação. Diretrizes Curriculares da Educação Básica - GEOGRAFIA. Curitiba: Seed/DEB-PR, 2008. Disponível em: <http://www.educadores.diaadia.pr.gov.br/arquivos/File/diretrizes/dce_geo.pdf> Acesso em: 19 de mai. de 2019.

. Secretaria de Estado da Educação. Caderno de Expectativas de Aprendizagem. Curitiba: Seed/DEB-PR, 2012. Disponível em: <http://www.educadores.diaadia.pr.gov.br/arquivos/File/diretrizes/caderno_expectativas.pdf> Acesso em: 22 de mai. de 2019.

PIZZATO, Maria Dilonê. Espírito e os propósitos do ensino da geografia, segundo as diretrizes curriculares nacionais para o ensino médio, preconizadas pela nova Lei de Diretrizes e Bases da Educação Nacional (Lei 9.394/96). Maringá, 2001. 94f. Dissertação de Mestrado - UEM.

PONTUSCHKA, Nídia Nacib; PAGANELLI, Tomoko lyda; CACETE, Núria Hanglei. Para ensinar e aprender geografia. 1 ed. São Paulo: Cortez: 2007.

. Parâmetros Curriculares Nacionais: tensão entre Estado e escola. In: CARLOS, Ana Fani Alessandri.; OLIVEIRA, Ariovaldo Umbelino de. (Orgs.) Reformas no mundo da educação: parâmetros curriculares e geografia. São Paulo: Contexto, 1999. p. 11-18.

. A geografia: pesquisa e ensino. In: CARLOS, Ana Fani Alessandri. Novos caminhos da Geografia. São Paulo: Contexto, 2002.

ROCHA, Genylton Odilon Rego da. A trajetória da disciplina geografia no currículo escolar brasileiro (1837-1942). 1996. 300f. Dissertação de Mestrado - PUC-SP, São Paulo, 1996.

SACRISTÁN, José Gimeno. O currículo: uma reflexão sobre a prática. 3 ed. Porto Alegre: Penso, 2017.

SPOSITO, Maria Encarnação Beltrão. Parâmetros Curriculares Nacionais para o ensino de geografia: pontos e contrapontos para uma análise. In: CARLOS, Ana Fani Alessandri.; OLIVEIRA, A. U. (Orgs.). Reformas no mundo da educação: parâmetros curriculares e geografia. São Paulo: Contexto, 1999. p. 19-35.

STRAFORINI, Rafael. Ensinar geografia: o desafio da totalidade-mundo nas séries iniciais. São Paulo: Annablume, 2004.

VESENTINI, José William. Realidades e perspectivas do ensino de Geografia no Brasil. In: VESENTINI, José William. (Org.) O ensino de geografia no século XXI. Campinas: Papirus, 2004. p. 219-248.

VLACH, Vânia. O ENSINO DE GEOGRAFIA NO BRASIL: UMA PERSPECTIVA HISTÓRICA. In: VESENTINI, José William (Org.) 0 ensino de geografia no século XXI. Campinas: Papirus, 2004. p. 187-218.

VYGOTSKY, L. S. Pensamento e linguagem. São Paulo: Martins Fontes,1993.

YOUNG, Michael F. D. Para que servem as escolas? Educ. Soc., Campinas, v. 28, n. 101, p. 1287-1302, set./dez. 2007. Disponível em: <http://www.scielo.br/pdf/es/v28n101/a0228101.pdf> Acesso em: 6 de mai. de 2019.

. O futuro da educação em uma sociedade do conhecimento: o argumento radical em defesa de um currículo centrado em disciplinas*. Revista Brasileira de Educação, Rio de Janeiro, v. 16, n. 48, p. 609-623, set./dez. 2011. Disponível em: <http://www.scielo.br/pdf/rbedu/v16n48/v16n48a05.pdf> Acesso em: 2 de mai. de 2019.

. Por que o conhecimento é importante para as escolas do século XXI? Cadernos de Pesquisa, São Paulo, v. 46, n. 159 , p. 18 37, jan./mar. 2016. Disponível em: <http://www.scielo.br/pdf/cp/v46n159/1980-5314-cp-46-159-00018.pdf> Acesso em: 6 de mai. de 2019. 